\section{Cureus}

Received 09/01/2015

Review began 09/06/2015

Review ended 09/22/2015

Published 10/07/2015

\section{(c) Copyright 2015}

Lock et al. This is an open access article distributed under the terms of the Creative Commons Attribution License CC-BY 3.0., which permits unrestricted use, distribution, and reproduction in any medium, provided the original author and source are credited.

\title{
Abscopal Effects: Case Report and Emerging Opportunities
}

\author{
Michael Lock ${ }^{1}$, Ahmad Muinuddin ${ }^{2}$, Walter I. Kocha ${ }^{3}$, Robert Dinniwell ${ }^{4}$, George Rodrigues \\ 5 , David D'Souza 6
}

1. Department of Radiation Oncology, London Regional Cancer Program, London, Ontario, CA; Schulich School of Medicine \& Dentistry, Western University, London, Ontario, CA. 2. Oncology, Trillium Health Partners 3. Oncology, London Health Sciences Centre 4. Cancer Clinical Research Unit (CCRU), Princess Margaret Cancer Centre 5. Department of Radiation Oncology, London Regional Cancer Program, London, Ontario, CA; Schulich School of Medicine \& Dentistry, Western University, London, Ontario, CA 6. Department of Radiation Oncology, London Regional Cancer Program, London, Ontario, CA

$\square$ Corresponding author: Michael Lock, michael.lock@lhsc.on.ca Disclosures can be found in Additional Information at the end of the article

\section{Abstract}

The abscopal effect is a phenomenon observed in the treatment of metastatic cancer where localized irradiation of a particular tumor site causes a response in a site distant to the irradiated volume. The mechanisms of the abscopal effect are speculated to be of several origins, including distant effects on p53, elaboration of inflammatory agents including cytokines, and, most recently, secondary to immune mechanisms. In this case report, we present a rare report of a patient with hepatocellular carcinoma with lung metastases who, after receiving radiation treatment to the liver, had a treatment response in the liver and a complete response in the lung. Recent advances in the understanding of the primary role of immune-modulated cytotoxicity, especially with the success of immune checkpoint inhibitors, have the potential to turn the abscopal effect from a rare phenomenon into a tool to guide antineoplastic therapy and provide a new line of research.

Categories: Radiation Oncology, Oncology

Keywords: abscopal effect, lung metastases, radiotherapy, liver cancer, spontaneous regression, immunomodulation, immune checkpoint inhibitors, sbrt, lung tumors

\section{Introduction}

Hepatocellular carcinoma (HCC) is the sixth most common malignancy worldwide, and the third most common cause of death from cancer [1]. The abscopal effect is a phenomenon rarely observed in the treatment of metastatic cancer where localized irradiation of a particular tumor site causes a response in a site distant to the irradiated area. Here, we describe a case report of a gentleman with HCC and lung metastases who, after receiving only focal radiation treatment to the liver, had complete and sustained radiological regression of pulmonary metastases.

The London Health Sciences Centre Research Ethics Board approved this study (approval \#16487E). Patient information was collected and released under an ethics approved prospective database.

\section{Case Presentation}

In early December 2009, a 71-year-old man presented to the Emergency Department with dyspnea as well as right-sided chest wall and upper quadrant abdominal pain. He was 


\section{Cureus}

diagnosed with pulmonary embolus and started on anticoagulation. His imaging investigations revealed multiple coalesced masses in the liver with the largest measuring $6 \mathrm{~cm} \mathrm{x} 9 \mathrm{~cm} \times 9 \mathrm{~cm}$ in the right lobe of the liver. Multiple lesions were also noted in the lung with bilateral pleural plaques consistent with asbestos exposure (Figure 1A). Alpha-fetoprotein (AFP) was significantly elevated at $11460 \mu \mathrm{g} / \mathrm{L}$ (normal less than 5). In late December, a liver biopsy was performed and pathology was diagnostic for primary HCC. He was diagnosed with Stage IV T3N0M1 disease. His past medical history was only significant for hypertension and Type 2 diabetes. He was an ex-smoker and quit in 1968. He was a retired boilermaker with asbestos exposure. 


\section{Cureus}

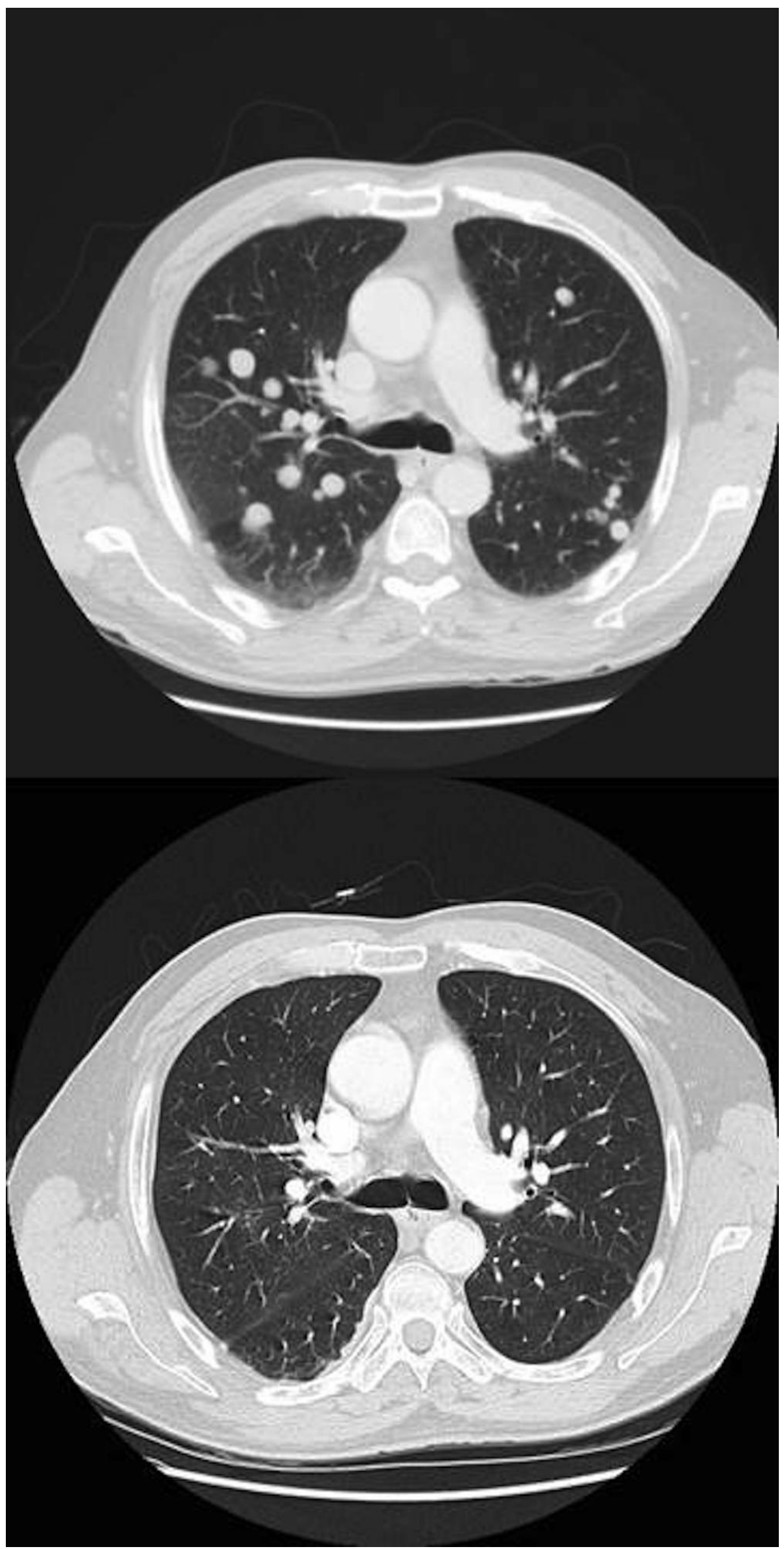

FIGURE 1: The axial CT scans of the thorax before and after 


\section{radiation of the liver.}

Figure 1A (top) The February 2010 axial CT thorax demonstrates multiple metastases before radiation .

Figure 1B (bottom) The August 2010 axial CT thorax demonstrates resolution of metastases five months after radiation .

In late January 2010, he met with a liver surgeon. A repeat CT scan of the thorax and abdomen in early February revealed the liver lesions had increased in size with the primary lesion now measuring greater than $14 \mathrm{~cm}$. Furthermore, there was evidence of worsening metastatic disease in the lungs with innumerable lesions between 0.5 and $2 \mathrm{~cm}$ in size. These were noncalcified and non-cavitary lesions. With this rapid doubling time, there was some debate within the Multidisciplinary Tumor Board about the role of medical treatment with sorafenib. The patient was ECOG 1 and had only mild hepatomegaly. He had no jaundice or stigmata of liver disease but was experiencing significant fatigue. Liver enzymes were minimally elevated with ALT $31 \mathrm{IU} / \mathrm{L}$ (normal less than 40), AST 73 IU/L (normal less than 41), ALP 95 IU/L (normal less than 129), and total bilirubin $8.1 \mu \mathrm{mol} / \mathrm{L}$ (normal less than 17). His albumin was $35 \mathrm{~g} / \mathrm{L}$ and INR was normal. His Child-Pugh Score was A6. However, the combination of his hypertension and anticoagulation raised the concern of increased bleeding risk and potential difficulty controlling hypertension while on sorafenib. Therefore, in conjunction with the patient, it was decided to go ahead with radiotherapy alone.

The patient underwent 70 Gy treatment in 15 fractions to the liver, which was completed in April 2010 (Figure 2). A follow-up CT abdomen in June 2010 showed the largest liver lesion had now shrunk from over $14 \mathrm{~cm}$ to $3 \mathrm{~cm}$. The patient was clinically stable and asymptomatic. Biochemically, the AFP had decreased to $196.8 \mu \mathrm{g} / \mathrm{L}$. In August 2010, the CT thorax and abdomen demonstrated stable disease in the liver. Furthermore, there was a dramatic complete resolution of the numerous pulmonary metastases with no new nodules or masses seen (Figure 1B). The patient received no other treatments up to this assessment point (August 2010), including no systemic treatments. 


\section{Cureus}

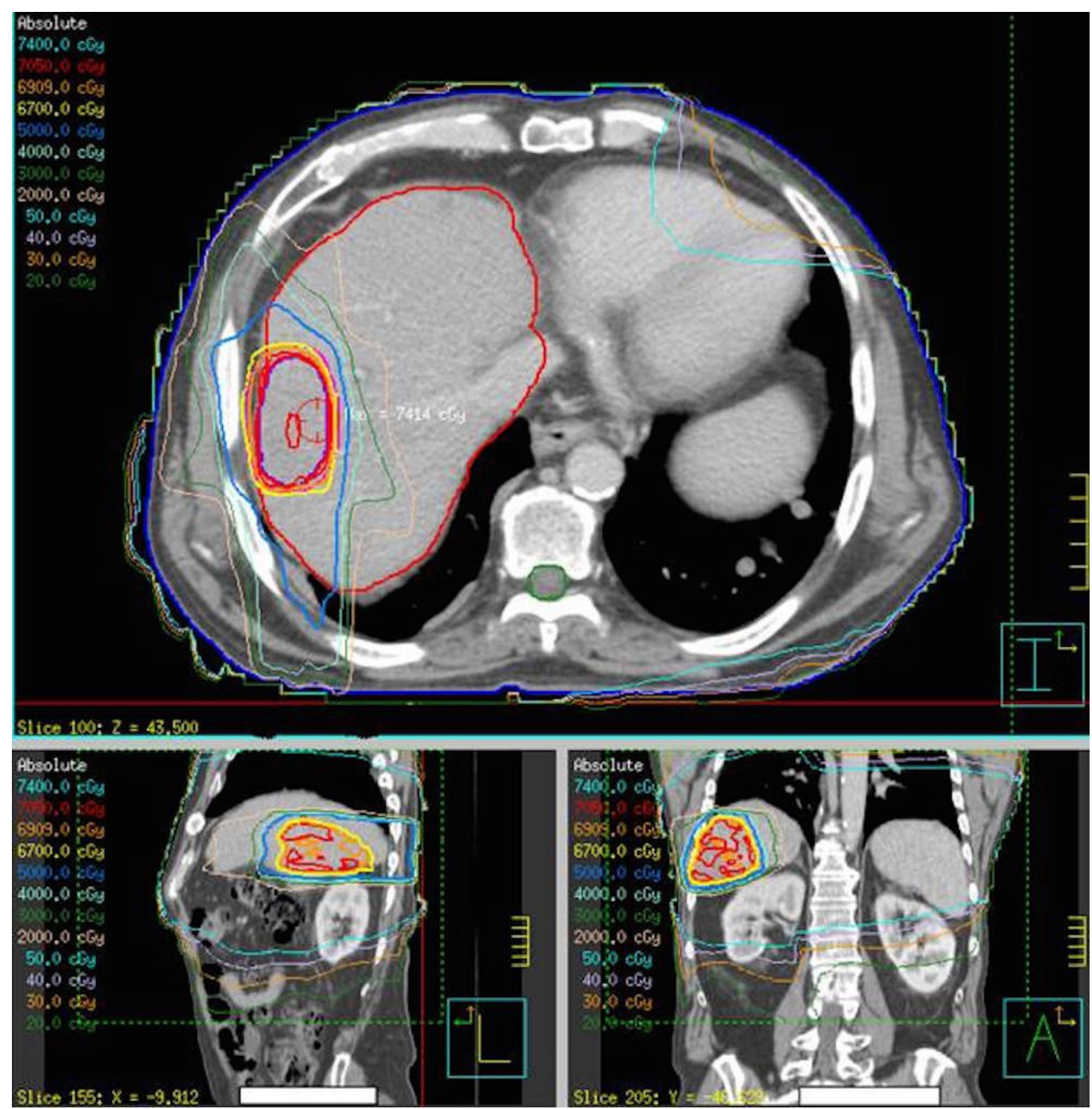

FIGURE 2: Radiation dosimetry plan for liver treatment

The patient underwent 70 Gy treatment in 15 fractions to the liver which was completed in April 2010.

From August 2010 till March 2012, the man enjoyed stable disease with normal liver laboratory results (including an AFP of 3.1) and no imaging evidence of disease recurrence. In March of 2012, a small recurrent nodule was found in the right liver and he underwent hepatic artery embolization with doxorubicin and cisplatin in May of 2012. This resulted in a complete response at that location.

\section{Discussion}

In 1953, Mole described the phenomena of abscopal effect as an "action at a distance from the irradiated volume, but within the same organism" [2]. It can result in a tumor in a nonirradiated area being spontaneously reduced. Since Mole's original account, many cases of the abscopal effect have been described in multiple tumor sites, including lymphoma and melanoma [3-4]. Though there are some reports of abscopal effect in hepatocellular carcinoma, these primarily report regression of hepatocellular carcinoma itself due to radiation treatment delivered at a metastatic site or with systemic treatment [5-10]. To our knowledge, ours is the first case report of the abscopal effect with focal liver radiation causing regression of distant 
lung metastasis in a systemic treatment naïve patient with HCC.

One interesting report in the literature describes a man with HCC who had a mediastinal metastasis and a pulmonary mass in the right lower lobe. After receiving focused mediastinal radiation, the abscopal effect was observed with regression of the pulmonary mass, which was not in the irradiated field [10]. However, in this case, the patient was first treated with a transcatheter arterial embolization, and hence, it is unclear if this treatment may have contributed to the response. This is different from our case, in which the patient was naïve to any treatment and received radiation treatment to the liver only, with subsequent regression of distant lung metastases. A limitation of our case report is that there was no pathologic confirmation for the metastatic disease in the lungs. However, the CT images (Figure 1A) reported by the radiologists were convincing and consistent with the common "cannon ball" lesions seen in lung metastasis.

The mechanism of the abscopal effect is still not well understood, although major mechanistic categories have been proposed and opportunities for exploitation reviewed [11-37]. These include involvement of the immune system, cytokines, tumor growth inhibition, and tumoricidal effects [16, 25, 38-39]. One proposed mechanism is that the irradiation of one tumor site results in the release of circulating tumor antigens and inflammatory factors that then mediate an augmented immune response against non-irradiated malignant lesions that express the same tumor antigens [40-41]. A French study [42] investigated the radiationinduced inflammatory response in mice after total abdominal or total-body irradiation. A systemic inflammatory reaction was found after abdominal and total-body irradiation in these mice, concomitant with increased cytokine and chemokine production in the jejunum and also in the lungs [42].

More recently, the observation of unexpected abscopal response in patients receiving radiation during immunotherapy has attracted much interest. Many of these mechanisms have explicit support from animal studies [40, 43-50, 65]. There is considerable insight into the mechanisms of synergistic activity between radiation immunogenic cell death and other biological effects. There appears to be a promotion of $\mathrm{T}$ cell recruitment and function associated with irradiation [51-52]. Roles for TGF- $\beta$ [53], involvement of p53 [54-57], and local tumor damage exposing previously hidden antigens have been implicated [40-41]. Upregulation of cytokines has also been demonstrated [38-39]. Immune checkpoint research has shown remarkable clinical results and may play a principle role when combined with radiation [15, 58-59]. CTLA-4, an immune checkpoint protein, has been shown to downregulate the immune system. In landmark work by Dewan, anti-CTLA-4 antibodies were assessed with and without radiation [59]. Dewan demonstrated that immune checkpoint inhibition alone or radiation alone did not result in an abscopal effect. However, a combination of fractionated radiation and anti-CTLA-4 results in an abscopal effect [59]. Inhibition of the secondary tumor was proportional to CD8+ T cells showing tumor specific IFN-gamma production. This synergy with immune checkpoint inhibitors can result in the net effect on antibodies targeting inhibitory receptors on $\mathrm{T}$ cells $[4$, 58-64]. In a 2015 review of 13 preclinical and 24 clinical papers, Reynders, et al. found that time to a documented abscopal response was within 24 months (median of 5 months). The response was maintained for 3-39 months (median of 13 months) [65].

\section{Conclusions}

We have reported a case of abscopal effect with focal radiation therapy to the liver causing regression of distant pulmonary metastasis in HCC. There is increasing evidence supporting the mechanisms of the abscopal effect as an immune-mediated process initiated by high-dose radiation. The recent elaboration and utility of immune checkpoint inhibitors in clinical practice provides significant optimism of a role of radiotherapy in combination with these therapies. This is a promising area of research and therapeutic development, which could lead 
us to take advantage of these phenomena in the treatment of cancer.

\section{Additional Information Disclosures}

Human subjects: Consent was obtained by all participants in this study. London Health Sciences Centre Research Ethics Board issued approval 16487E. Conflicts of interest: In compliance with the ICMJE uniform disclosure form, all authors declare the following: Payment/services info: All authors have declared that no financial support was received from any organization for the submitted work. Financial relationships: All authors have declared that they have no financial relationships at present or within the previous three years with any organizations that might have an interest in the submitted work. Other relationships: All authors have declared that there are no other relationships or activities that could appear to have influenced the submitted work.

\section{References}

1. Jemal A, Siegel R, Ward E, Murray T, Xu J, Thun MJ: Cancer statistics, 2007. CA Cancer J Clin. 2007, 57:43-66. 10.3322/canjclin.57.1.43

2. Mole RH: Whole body irradiation radiobiology or medicine?. Br J Radiol. 1953, 26:234-41. 10.1259/0007-1285-26-305-234

3. Perego D, Faravelli A: Unexpected consequence of splenectomy in composite lymphoma. The abscopal effect. Haematologica. 2000, 85:211.

4. Postow MA, Callahan MK, Barker CA, Yamada Y, Yuan J, Kitano S, Mu Z, Rasalan T, Adamow M, Ritter E, Sedrak C, Jungbluth AA, Chua R, Yang AS, Roman RA, Rosner S, Benson B, Allison JP, Lesokhin AM, Gnjatic S, Wolchok JD: Immunologic correlates of the abscopal effect in a patient with melanoma. N Engl J Med. 2012, 366:925-31. 10.1056/NEJMoa1112824

5. Ikeda M OS, Ueno H, Okusaka T, Kuriyama H: Spontaneous regression of hepatocellular carcinoma with multiple lung metastases: a case report. Jpn J Clin Oncol. 2001, 31:454-58. 10.1093/jjco/hye092

6. Ohba K, Omagari K, Nakamura T, Ikuno N, Saeki S, Matsuo I, Kinoshita H, Masuda J, Hazama H, Sakamoto I, Kohno S: Abscopal regression of hepatocellular carcinoma after radiotherapy for bone metastasis. Gut. 1998, 43:575-77. 10.1136/gut.43.4.575

7. Oquiñena S, Iñarrairaegui M, Vila JJ, Alegre F, Zozaya JM, Sangro B: Spontaneous regression of hepatocellular carcinoma: three case reports and a categorized review of the literature. Dig Dis Sci. 2009, 54:1147-53. 10.1007/s10620-008-0447-z

8. Miyanaga $\mathrm{O}$, Shirahama M, Ishibashi H: A case of remission in metastatic lung tumor from hepatocellular carcinoma after combined CDDP and PSK therapy (Article in Japanese). Gan No Rinsho. 1990, 36:527-31.

9. Nakanishi M, Chuma M, Hige S, Asaka M: Abscopal effect on hepatocellular carcinoma . Am J Gastroenterol. 2008, 103:1320-21.10.1111/j.1572-0241.2007.01782_13.x

10. Okuma K, Yamashita H, Niibe Y, Hayakawa K, Nakagawa K: Abscopal effect of radiation on lung metastases of hepatocellular carcinoma: a case report. J Med Case Rep. 2011, 5:111. 10.1186/1752-1947-5-111

11. Ahmed M: Localized radiation can induce systemic anti-cancer immune and non-immune responses and how we might utilize it. Med Phys. 2015, 42:3609. 10.1118/1.4925613

12. Bloy N, Pol J, Manic G, Vitale I, Eggermont A, Galon J, Tartour E, Zitvogel L, Kroemer G, Galluzzi L: Trial Watch: Radioimmunotherapy for oncological indications . Oncoimmunology. 2014, 3:e954929. 10.4161/21624011.2014.954929

13. Blyth BJ, Sykes PJ: Radiation-induced bystander effects: what are they, and how relevant are they to human radiation exposures?. Radiat Res. 2011, 176:139-57. 10.1667/RR2548.1

14. Cheung P, Thibault I, Bjarnason GA: The emerging roles of stereotactic ablative radiotherapy for metastatic renal cell carcinoma. Curr Opin Support Palliat Care. 2014, 8:258-64. 10.1097/SPC.0000000000000074

15. Corvò R, Belgioia L: Synergy between radiotherapy and immunotherapy in the treatment of advanced malignancies: recent evidences of a new challenge in oncology (article in Italian). 
Recent Prog Med . 2015, 106:322-30. 10.1701/1940.21088

16. Demaria S, Formenti SC: Radiation as an immunological adjuvant: current evidence on dose and fractionation. Front Oncol. 2012, 2:153. 10.3389/fonc.2012.00153

17. Demaria S, Ng B, Devitt ML, Babb JS, Kawashima N, Liebes L, Formenti SC: Ionizing radiation inhibition of distant untreated tumors (abscopal effect) is immune mediated. Int J Radiat Oncol Biol Phys. 2004, 58:862-70. 10.1016/j.ijrobp.2003.09.012

18. Durante M, Reppingen N, Held KD : Immunologically augmented cancer treatment using modern radiotherapy. Trends Mol Med. 2013, 19:565-82. 10.1016/j.molmed.2013.05.007

19. Fernandez-Palomo C, Bräuer-Krisch E, Laissue J, Vukmirovic D, Blattmann H, Seymour C, Schültke E, Mothersill C: Use of synchrotron medical microbeam irradiation to investigate radiation-induced bystander and abscopal effects in vivo. Phys Med. 2015, 31:584-95. 10.1016/j.ejmp.2015.03.004

20. Fransen MF, Ossendorp F, Arens R, Melief CJ: Local immunomodulation for cancer therapy: Providing treatment where needed. Oncoimmunology. 2013, 2:e26493. 10.4161/onci.26493

21. Frey B, Rubner Y, Kulzer L, Werthmöller N, Weiss EM, Fietkau R, Gaipl US: Antitumor immune responses induced by ionizing irradiation and further immune stimulation. Cancer Immunol Immunother. 2014, 63:29-36. 10.1007/s00262-013-1474-y

22. Frey B, Rubner Y, Wunderlich R, Weiss EM, Pockley AG, Fietkau R, Gaipl US: Induction of abscopal anti-tumor immunity and immunogenic tumor cell death by ionizing irradiation implications for cancer therapies. Curr Med Chem. 2012, 19:1751-64.

10.2174/092986712800099811

23. Hanna GG, Coyle VM, Prise KM: Immune modulation in advanced radiotherapies: Targeting out-of-field effects. Cancer Lett. 2015, 368:246-51. 10.1016/j.canlet.2015.04.007

24. Hutchinson L: Radiotherapy: Abscopal responses: pro-immunogenic effects of radiotherapy . Nat Rev Clin Oncol. 2015, 12:504. 10.1038/nrclinonc.2015.127

25. Kaminski JM, Shinohara E, Summers JB, Niermann KJ, Morimoto A, Brousal J: The controversial abscopal effect. Cancer Treat Rev. 2005, 31:159-72. 10.1016/j.ctrv.2005.03.004

26. Ludgate CM: Optimizing cancer treatments to induce an acute immune response: radiation abscopal effects, PAMPs, and DAMPs. Clin Cancer Res. 2012, 18:4522-25. 10.1158/10780432.CCR-12-1175

27. Mancuso M, Giardullo P, Leonardi S, Pasquali E, Casciati A, De Stefano I, Tanori M, Pazzaglia $\mathrm{S}$, Saran A: Dose and spatial effects in long-distance radiation signaling in vivo: implications for abscopal tumorigenesis. Int J Radiat Oncol Biol Phys. 2013, 85:813-19. 10.1016/j.ijrobp.2012.07.2372

28. Mancuso M, Pasquali E, Giardullo P, Leonardi S, Tanori M, Di Majo V, Pazzaglia S, Saran A: The radiation bystander effect and its potential implications for human health. Curr Mol Med. 2012, 12:613-24. 10.2174/156652412800620011

29. Marín A, Martín M, Liñán O, Alvarenga F, López M, Fernández L, Büchser D, Cerezo L: Bystander effects and radiotherapy. Rep Pract Oncol Radiother. 2015, 20:12-21. 10.1016/j.rpor.2014.08.004

30. Park B, Yee C, Lee KM: The effect of radiation on the immune response to cancers . Int J Mol Sci. 2014, 15:927-43. 10.3390/ijms15010927

31. Reese AS, Feigenberg SJ, Husain A, Webb TJ, Hausner PF, Edelman MJ, Feliciano J, Tkaczuk $\mathrm{KH}$, Sharma NK: Stereotactic ablative radiotherapy (SABR) impact on the immune system and potential for future therapeutic modulation. Mol Cell Pharmacol. 2013, 5:19-25.

32. Rödel F, Frey B, Multhoff G, Gaipl U: Contribution of the immune system to bystander and non-targeted effects of ionizing radiation. Cancer Lett. 2015, 356:105-13.

10.1016/j.canlet.2013.09.015

33. Seyedin SN, Tang C, Welsh JW: Author's view radiation and immunotherapy as systemic therapy for solid tumors. Oncoimmunology. 2015, 4:e986402. 10.4161/2162402X.2014.986402

34. Siva S, MacManus MP, Martin RF, Martin OA: Abscopal effects of radiation therapy: a clinical review for the radiobiologist. Cancer Lett. 2015, 356:82-90. 10.1016/j.canlet.2013.09.018

35. Tang C, Wang X, Soh H, Seyedin S, Cortez MA, Krishnan S, Massarelli E, Hong D, Naing A, Diab A, Gomez D, Ye H, Heymach J, Komaki R, Allison JP, Sharma P, Welsh JW: Combining radiation and immunotherapy: a new systemic therapy for solid tumors?. Cancer Immunol Res. 2014, 2:831-38. 10.1158/2326-6066.CIR-14-0069

36. Vatner RE, Cooper BT, Vanpouille-Box C, Demaria S, Formenti SC: Combinations of immunotherapy and radiation in cancer therapy. Front Oncol. 2014, 4:325. 
37. Zeng J, Harris TJ, Lim M, Drake CG, Tran PT: Immune modulation and stereotactic radiation: improving local and abscopal responses. Biomed Res Int. 2013, 2013:658126.

$10.1155 / 2013 / 658126$

38. Golden EB, Chhabra A, Chachoua A, Adams S, Donach M, Fenton-Kerimian M, Friedman K, Ponzo F, Babb JS, Goldberg J, Demaria S, Formenti SC: Local radiotherapy and granulocytemacrophage colony-stimulating factor to generate abscopal responses in patients with metastatic solid tumours: a proof-of-principle trial. Lancet Oncol. 2015, 16:795-803. 10.1016/S1470-2045(15)00054-6

39. Rastogi S, Coates PJ, Lorimore SA, Wright EG: Bystander-type effects mediated by long-lived inflammatory signaling in irradiated bone marrow. Radiat Res. 2012, 177:244-50. 10.1667/RR2805.1

40. Shiraishi K, Ishiwata Y, Nakagawa K, Yokochi S, Taruki C, Akuta T, Ohtomo K, Matsushima K, Tamatani T, Kanegasaki S: Enhancement of antitumor radiation efficacy and consistent induction of the abscopal effect in mice by ECI301, an active variant of macrophage inflammatory protein-1alpha. Clin Cancer Res. 2008, 14:1159-66. 10.1158/1078-0432.CCR07-4485

41. Albanese J, Dainiak N: Ionizing radiation alters Fas antigen ligand at the cell surface and on exfoliated plasma membrane-derived vesicles: implications for apoptosis and intercellular signaling. Radiat Res. 2000, 153:49-61. 10.1667/0033-7587(2000)153[0049:IRAFAL]2.0.CO;2

42. Van der Meeren A MP, Vandamme M, Squiban C, Wysocki J, Griffiths N: Abdominal radiation exposure elicits inflammatory responses and abscopal effects in the lungs of mice. Radiat Res. 2005, 163:144-52. 10.1667/RR3293

43. Akutsu Y, Matsubara H, Urashima T, Komatsu A, Sakata H, Nishimori T, Yoneyama Y, Hoshino I, Murakami K, Usui A, Kano M, Ochiai T: Combination of direct intratumoral administration of dendritic cells and irradiation induces strong systemic antitumor effect mediated by GRP94/gp96 against squamous cell carcinoma in mice. Int J Oncol. 2007, 31:50915. 10.3892/ijo.31.3.509

44. Aravindan S, Natarajan M, Ramraj SK, Pandian V, Khan FH, Herman TS, Aravindan N: Abscopal effect of low-LET gamma-radiation mediated through Rel protein signal transduction in a mouse model of nontargeted radiation response. Cancer Gene Ther. 2014, 21:54-9. 10.1038/cgt.2013.72

45. Hodge JW, Sharp HJ, Gameiro SR: Abscopal regression of antigen disparate tumors by antigen cascade after systemic tumor vaccination in combination with local tumor radiation. Cancer Biother Radiopharm. 2012, 27:12-22.10.1089/cbr.2012.1202

46. Kurnick NB, Nokay N: Abscopal effects of X-irradiation on mouse bone marrow . Radiat Res. 1964, 23:239-48. 10.2307/3571605

47. Kurnick NB, Nokay N: Abscopal effects and bone-marrow repopulation in man and mouse . Ann N Y Acad Sci. 1964, 114:528-37. 10.1111/j.1749-6632.1964.tb53605.x

48. Mancuso M, Leonardi S, Giardullo P, Pasquali E, Tanori M, De Stefano I, Casciati A, Naus CC, Pazzaglia S, Saran A: Oncogenic radiation abscopal effects in vivo: interrogating mouse skin . Int J Radiat Oncol Biol Phys. 2013, 86:993-99. 10.1016/j.ijrobp.2013.04.040

49. Wachtel LW, Cole LJ: Abscopal effects of whole-body X-irradiation on compensatory hypertrophy of the rat kidney USNRDL-TR-783. Res Dev Tech Rep. 1964, 11:1-23.

50. Yasuda K, Nirei T, Tsuno NH, Nagawa H, Kitayama J: Intratumoral injection of interleukin-2 augments the local and abscopal effects of radiotherapy in murine rectal cancer. Cancer Sci. 2011, 102:1257-63. 10.1111/j.1349-7006.2011.01940.x

51. Demaria S, Formenti SC: Role of T lymphocytes in tumor response to radiotherapy . Front Oncol. 2012, 2:95. 10.3389/fonc.2012.00095

52. Demaria S, Vanpouille-Box C, Formenti SC, Adams S: The TLR7 agonist imiquimod as an adjuvant for radiotherapy-elicited in situ vaccination against breast cancer. Oncoimmunology. 2013, 2:e25997. 10.4161/onci.25997

53. Vanpouille-Box C, Diamond JM, Pilones KA, Zavadil J, Babb JS, Formenti SC, Barcellos-Hoff $\mathrm{MH}$, Demaria S: TGFbeta Is a master regulator of radiation therapy-induced a ntitumor immunity. Cancer Res. 2015, 75:2232-42. 10.1158/0008-5472.CAN-14-3511

54. Camphausen K, Moses MA, Ménard C, Sproull M, Beecken WD, Folkman J, O'Reilly MS: Radiation abscopal antitumor effect is mediated through p53. Cancer Res. 2003, 63:1990-93.

55. Lorimore SA, Rastogi S, Mukherjee D, Coates PJ, Wright EG: The influence of p53 functions 
on radiation-induced inflammatory bystander-type signaling in murine bone marrow. Radiat Res. 2013, 179:406-15. 10.1667/RR3158.2

56. Strigari L, Mancuso M, Ubertini V, Soriani A, Giardullo P, Benassi M, D'Alessio D, Leonardi S, Soddu S, Bossi G: Abscopal effect of radiation therapy: Interplay between radiation dose and p53 status. Int J Radiat Biol. 2014, 90:248-55. 10.3109/09553002.2014.874608

57. Strigari L, Mancuso M, Ubertini V, Soriani A, Giardullo P, Benassi M, D'Alessio D, Leonardi S, Soddu S, Bossi G: Corrigendum: Abscopal effect of radiation therapy: interplay between radiation dose and p53 status. Int J Radiat Biol. 2015, 91:294. 10.3109/09553002.2014.997514

58. Demaria S, Pilones KA, Formenti SC, Dustin ML: Exploiting the stress response to radiation to sensitize poorly immunogenic tumors to anti-CTLA-4 treatment. Oncoimmunology. 2013, 2:e23127. 10.4161/onci.23127

59. Dewan MZ, Galloway AE, Kawashima N, Dewyngaert JK, Babb JS, Formenti SC, Demaria S: Fractionated but not single-dose radiotherapy induces an immune-mediated abscopal effect when combined with anti-CTLA-4 antibody. Clin Cancer Res. 2009, 2:5379-88. 10.1158/10780432.CCR-09-0265

60. Hao Y, Cifter G, Altundal Y, Sinha N, Moreau M, Sajo E, Makrigiorgos G, Ngwa W: MO-FGBRA-04: Leveraging the abscopal effect via new design radiotherapy biomaterials loaded with immune checkpoint inhibitors. Med Phys. 2015, 42:3565. 10.1118/1.4925408

61. Park SS, Dong H, Liu X, Harrington SM, Krco CJ, Grams MP, Mansfield AS, Furutani KM, Olivier KR, Kwon ED: PD-1 Restrains Radiotherapy-Induced Abscopal Effect . Cancer Immunol Res. 2015, 3:610-19. 10.1158/2326-6066.CIR-14-0138

62. Pilones KA, Vanpouille-Box C, Demaria S: Combination of radiotherapy and immune checkpoint inhibitors. Semin Radiat Oncol. 2015, 25:28-33. 10.1016/j.semradonc.2014.07.004

63. Vanpouille-Box C, Pilones KA, Wennerberg E, Formenti SC, Demaria S: In situ vaccination by radiotherapy to improve responses to anti-CTLA-4 treatment. Vaccine. 2015, pub ahead of print:pii: S0264-410X(15)00911-1. 10.1016/j.vaccine.2015.05.105

64. Wu L, Wu MO, De la Maza L, Yun Z, Yu J, Zhao Y, Cho J, de Perrot M: Targeting the inhibitory receptor CTLA-4 on T cells increased abscopal effects in murine mesothelioma model. Oncotarget. 2015, 6:12468-80. 10.18632/oncotarget.3487

65. Reynders K, Illidge T, Siva S, Chang JY, De Ruysscher D: The abscopal effect of local radiotherapy: using immunotherapy to make a rare event clinically relevant. Cancer Treat Review. 2015, 41:503-10. 10.1016/j.ctrv.2015.03.011 